\title{
Correlation of Dry Deposition Velocity and Friction Velocity over Different Surfaces for PM2.5 and Particle Number Concentrations
}

\author{
Antonio Donateo and Daniele Contini \\ Istituto di Scienze dell'Atmosfera e del Clima, ISAC-CNR, U.O.S. di Lecce, Strada Provinciale Lecce-Monteroni km 1.2, \\ 73100 Lecce, Italy \\ Correspondence should be addressed to Antonio Donateo; a.donateo@isac.cnr.it
}

Received 6 March 2014; Accepted 18 May 2014; Published 1 June 2014

Academic Editor: Carlos Borrego

Copyright (C) 2014 A. Donateo and D. Contini. This is an open access article distributed under the Creative Commons Attribution License, which permits unrestricted use, distribution, and reproduction in any medium, provided the original work is properly cited.

Dry deposition of particles is an important way of aerosol removal from the atmosphere and a key process in surface-atmosphere exchanges. The deposition velocities, $\mathrm{Vd}$, are often parameterised in air quality and climate modelling as function of the friction velocity, $u^{*}$, atmospheric stability, and particle size (if size-segregated information is available). In this work, a study of the correlation between Vd and $u^{*}$ over different surfaces is presented for both PM2.5 and particle number fluxes. Results indicate an almost linear increase of $\mathrm{Vd}$ with $u^{*}$ with slopes similar for PM2.5 fluxes and particle number fluxes over the different surfaces analysed. This means that the ratios $\mathrm{Vd} / u^{*}$ tend to collapse over similar values even if $\mathrm{Vd}$ and $u^{*}$ are significantly different because $u^{*}$ take into account most of the surface effects. There is a limited difference between stable cases and unstable/neutral cases with slightly lower deposition velocities in stable cases for fixed values of $u^{*}$. The average value of $\mathrm{Vd} / u^{*}$ is $0.010 \pm 0.0017$ (median $0.0062 \pm 0.0015)$ (considering all stabilities) and $0.0097 \pm 0.002$ (median $0.005 \pm 0.001$ ) for stable cases. This could be the base for an empirical parameterisation of deposition velocities in air quality models.

\section{Introduction}

Atmospheric aerosol particles are generated by both anthropogenic and natural sources and through chemical and physical processes in the atmosphere. The dynamics of atmospheric aerosols is highly complex, involving particle formation, growth, and surface exchange processes [1]. Effects of aerosols include direct and indirect climate forcing through the absorption and scattering of incoming solar radiation and the formation of clouds by condensation nuclei activation [2, 3], reduction of visibility [4], and impact on human health [58]. Dry deposition of particles is a key process in atmospheresurface exchange. It is a continuous process that gives a significant contribution to atmospheric particles removal in most environments. The analysis and the parameterization of the processes affecting vertical transport and exchange of particles are a relevant research topic for air quality and climate modelling [9-11]. There are several possible methods to investigate dry deposition of aerosol; however, in the last several years the eddy-covariance method (EC) became widely used to investigate dry deposition velocities over several typologies of surfaces [12, 13]. EC has been used to characterise deposition velocities in rural sites and over forests $[12,14,15]$, over ice and snow [16-19], and in urban environments to characterise emission velocities (i.e., upward fluxes) [20-25].

There are several factors influencing dry deposition of aerosol, mainly the friction velocity, the particle size, boundary layer conditions (turbulence intensity), atmospheric stability, and collecting properties of the surface. There are many models that try to explain and parameterise the deposition process in complex surfaces by taking into account several mechanisms characterising turbulent fluxes [26-28]. In other cases, the simpler parameterisations of dry deposition velocities $\mathrm{Vd}$ as function of friction velocity $u^{*}$ and of stability (through the Monin-Obukhov length, $L$ ) are used [12, 13, 15]. These parameterisations could be used in transport and dispersion models to take into account the transfer of 


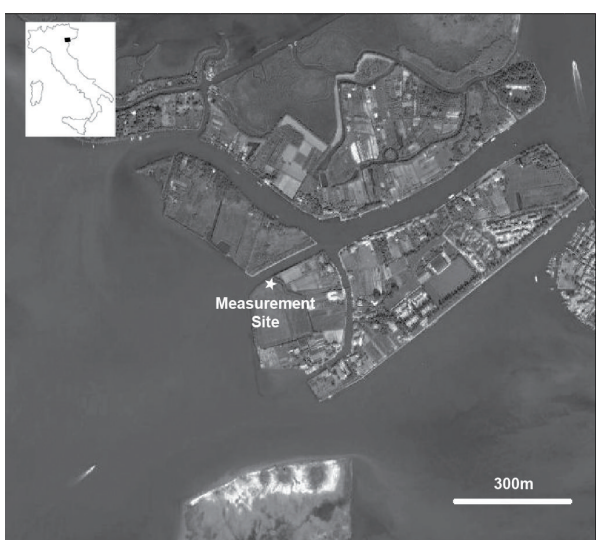

(a)

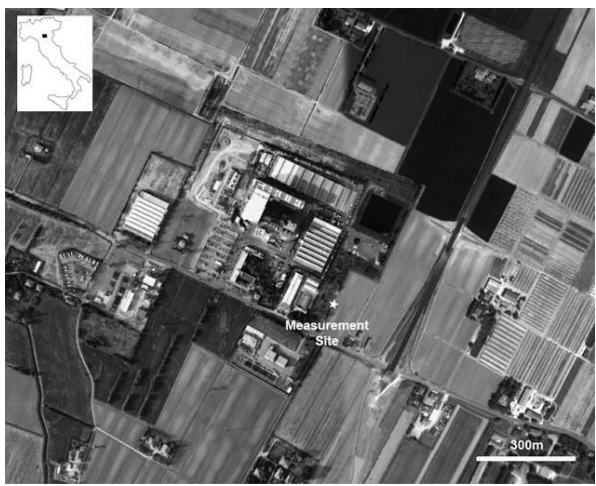

(c)

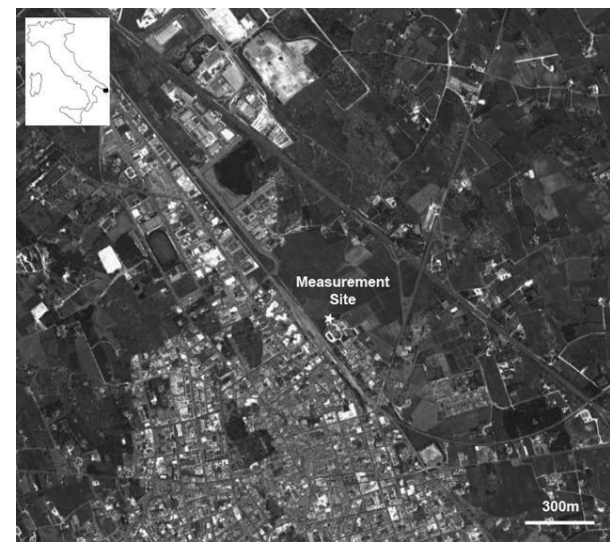

(e)

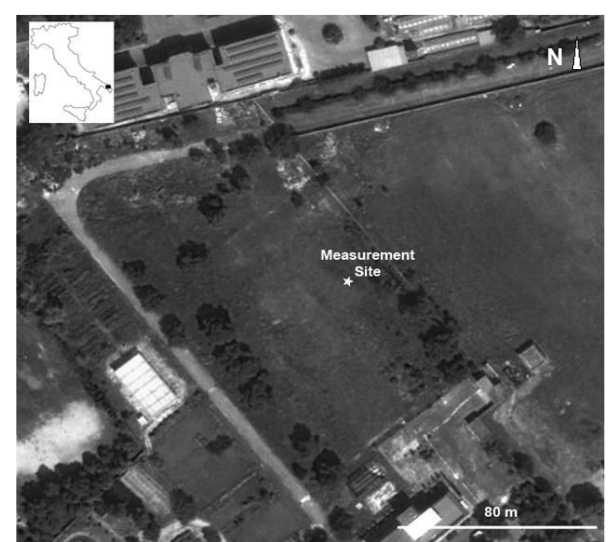

(b)

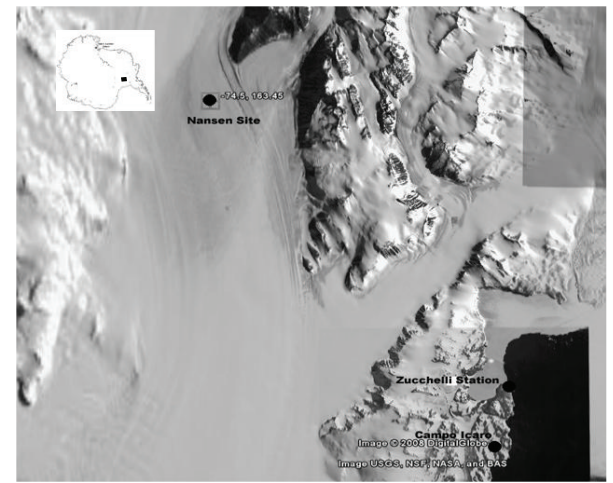

(d)

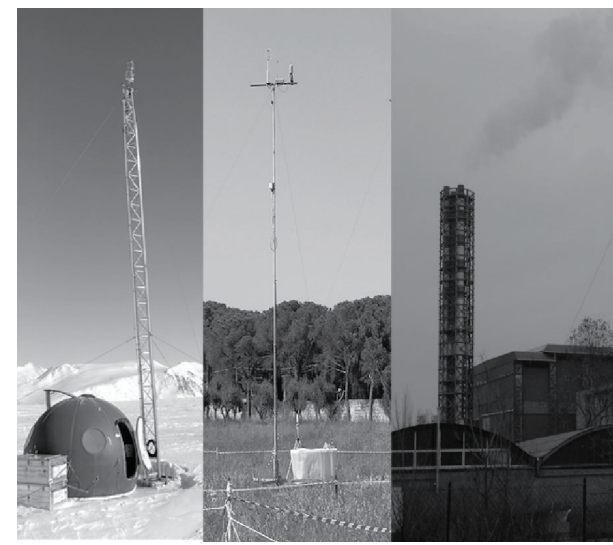

(f)

Figure 1: Maps from Google Earth @ for each measurement site. In order: (a) Venice lagoon, Mazzorbo island; (b) Lecce, University Campus; (c) Bologna, Frullo industrial district; (d) Antarctica, Nansen Ice Sheet; and (e) Maglie, suburban area. In (f) a series of the measurement setup images from the different sites, in particular Antarctica tower, a micrometeorological mast in Lecce, and the incinerator chimney in Frullo district.

materials from atmosphere to the surface. In general, the nondimensional ratio $\mathrm{Vd} / u^{*}$ appears to be smaller in stable atmospheric conditions with respect to unstable conditions [29].

In this work an analysis of the correlation between dry deposition velocities, taken over different surfaces, and friction velocities as function of stability is discussed. Measurements refer to both PM2.5 mass fluxes and particle number fluxes.

\section{Measurement Sites}

The datasets analyzed in this work were taken in different experimental campaigns over a wide range of surface roughness conditions, from almost smooth surfaces (i.e., iced surfaces in Antarctica) to surfaces with different degrees of complexity: urban background, urban canopy, and industrial district (in Italy) or patchy Venice lagoon surface (Italy). In the following sections each experimental site and campaign 
TABLE 1: Summary of experimental sites and instruments used in aerosol sampling. The table includes the details of the set-up, such as measurement height $(z)$, displacement height $(d)$, and roughness length $\left(z_{0}\right)$.

\begin{tabular}{lcccc}
\hline Site & Instruments & Height $z(\mathrm{~m})$ & $\begin{array}{c}\text { Displacement } \\
\text { height } d(\mathrm{~m})\end{array}$ & $\begin{array}{c}\text { Roughness length } \\
z_{0}(\mathrm{~m})\end{array}$ \\
\hline Antarctica & CPC Grimm 5.403 & 12 & 0 & $0.0002 \pm 0.0001$ \\
\hline Venice lagoon & pDR-1200 Thermo-MIE & 9.6 & $\begin{array}{c}5.1 \pm 0.5 \text { land } \\
\text { 0 water }\end{array}$ & $\begin{array}{c}0.11 \pm 0.03 \text { land } \\
0.01 \pm 0.03 \text { water }\end{array}$ \\
\hline Bologna & CPC Grimm 5.403 & 10 & $4.8 \pm 0.5$ & $0.35 \pm 0.02$ \\
\hline $\begin{array}{l}\text { Lecce (2005) } \\
\text { Lecce (2010) }\end{array}$ & $\begin{array}{c}\text { pDR-1200 Thermo-MIE } \\
\text { CPC Grimm 5.403 }\end{array}$ & 10 & $6.1 \pm 0.4$ & $0.53 \pm 0.02$ \\
\hline Maglie & pDR-1200 Thermo-MIE & 10 & $6 \pm 0.5$ & $0.52 \pm 0.02$ \\
\hline
\end{tabular}

TABLE 2: Summary of experimental sites with indication of the typology of measurements. The table includes the percentages associated with the different corrections such as density fluctuation correction, high frequency loss correction, and nonstationary data removed.

\begin{tabular}{lcccc}
\hline Site & Measurements & $\begin{array}{c}\text { Density fluctuation } \\
\text { correction (\%) }\end{array}$ & $\begin{array}{c}\text { Nonstationary } \\
\text { data (\%) }\end{array}$ & $\begin{array}{c}\text { High frequency loss } \\
\text { correction (\%) }\end{array}$ \\
\hline Antarctica & Particle number & 3.4 & 15 & 43 \\
Venice lagoon & PM2.5 & Not applied & 6 & 27 \\
Bologna & Particle number & Not applied & 18 & 30 \\
Lecce 2005 & PM2.5 & Not applied & 5 & 20 \\
Lecce 2010 & Particle number & 0.2 & 6 & 23 \\
Maglie & PM2.5 & Not applied & 8 & 24 \\
\hline
\end{tabular}

have been briefly described and the details of the sites characteristics are summarised in Table 1 and shown in Figure 1. The micrometeorological measurements were used to evaluate the displacement height $d$ and the roughness height $z_{0}$ for each site (Table 1 ) using the method reported in [30], which uses similarity relationship for sonic temperature and vertical wind component.

\subsection{Venice Lagoon (Mazzorbo Island, North-Eastern Italy).} Measurements of PM2.5 concentrations and fluxes were performed at a background site placed on the island of Mazzorbo, in the Venice lagoon at $10 \mathrm{~m}$ above the ground. The measurement site $\left(45^{\circ} 29^{\prime} 09.5^{\prime \prime} \mathrm{N}, 12^{\circ} 24^{\prime} 12.7^{\prime \prime} \mathrm{E}\right)$ was a field located at about $8 \mathrm{~km} \mathrm{NE}$ of the Venice town. This site was located very close (about $5 \mathrm{~m}$ ) to the water lagoon at the W-SW side, while, in the other directions (north, east, and south), it was characterised by land for about $1-2 \mathrm{~km}$ with short vegetation, some small trees, and one or two-floor houses, although channels and water were also present in this area (Figure 1(a)). Three measurement campaigns were performed: the first measurement campaign (summer) in July 2004 (2 to 18), the second campaign (winter) in February and March 2005 (16 February to 15 March), and the third campaign (spring) in May 2006 (5 to 23). These campaigns are analysed together in this work. More details on the site can be found in [31].

2.2. Lecce Urban Background Site (South-Eastern Italy). A measurement campaign was performed during spring/summer 2005 form April until June relative to PM2.5 concentrations and fluxes. A second campaign was performed between 12 and 30 July, 2010 for measurements of particle number concentrations and fluxes. The site was the experimental field of the Lecce Unit of ISAC-CNR placed inside the University Campus $\left(40^{\circ} 20^{\prime} 10.8^{\prime \prime} \mathrm{N}, 18^{\circ} 07^{\prime} 21.0^{\prime \prime} \mathrm{E}\right)$ and located at about $3.5 \mathrm{~km} \mathrm{SW}$ from the town of Lecce. The site is a rectangular field with a major side of about $200 \mathrm{~m}$ characterized by short vegetation, with two contiguous sides surrounded by small trees (Figure 1(b)). The urban background area is characterized for at least $1 \mathrm{~km}$ in all directions by the presence of patches of trees $(8-10 \mathrm{~m}$ tall) and small two-storey buildings and some roads with no industrial releases nearby. Due to the proximity of urban areas, the site can be categorized as an urban background area. Measurements were taken at $10 \mathrm{~m}$ above the ground. More details on this site can be found in [32] or [33].

2.3. Bologna Industrial District (Central Italy). Measurements of particle number concentration and fluxes were taken between 6 June and 22 July 2008 (summer campaign) and from 20 January to 10 March 2009 (winter campaign). Nearby measurement site, on left of Mobile Laboratory in Figure 1(c), there was the incinerator plant for the city of Bologna $\left(44^{\circ} 31^{\prime} 17.59^{\prime \prime} \mathrm{N}, 11^{\circ} 25^{\prime} 53.48^{\prime \prime} \mathrm{E}\right)$. The two campaigns are analysed together in this work.

2.4. Antarctica Remote Site. The data, relative to particle number concentrations and fluxes, were collected over ice/snow surface in Antarctica during austral summer in 2006 in the framework of the Italian National Research Program in Antarctica (PNRA). Measurements were performed on the Nansen Ice Sheet (NIS), a coastal region of the Northern 
TABLE 3: Average (with standard deviation) and median (with 25th and 75th quartiles) values are reported for deposition velocities, fluxes, concentrations, and normalized deposition velocities for each site, separating PM2.5 from particle number data. In this table all data is considered, without any selection involving stability conditions.

\begin{tabular}{|c|c|c|c|c|c|}
\hline \multicolumn{6}{|c|}{ All stability conditions } \\
\hline \multicolumn{2}{|c|}{ PM2.5 } & $\mathrm{Vd}(\mathrm{mm} / \mathrm{s})$ & Flux $\left(\mu \mathrm{g} / \mathrm{m}^{2} \mathrm{~s}\right)$ & Conc. $\left(\mu \mathrm{g} / \mathrm{m}^{3}\right)$ & $\mathrm{Vd} / u^{*}$ \\
\hline \multirow{5}{*}{ Venice } & Average & 2.81 & -0.040 & 26.4 & 0.0108 \\
\hline & Std. dev. & 4.70 & 0.064 & 25.5 & 0.0155 \\
\hline & Median & 1.19 & -0.017 & 18.0 & 0.0048 \\
\hline & 25th quartile & 0.38 & -0.044 & 8.6 & 0.0019 \\
\hline & 75th quartile & 3.11 & -0.006 & 35.4 & 0.0140 \\
\hline \multirow{5}{*}{ Lecce 2005} & Average & 4.32 & -0.031 & 10.2 & 0.0103 \\
\hline & Std. dev. & 6.16 & 0.047 & 5.9 & 0.0131 \\
\hline & Median & 2.04 & -0.019 & 9.8 & 0.0054 \\
\hline & 25th quartile & 0.85 & -0.039 & 5.4 & 0.0025 \\
\hline & 75th quartile & 4.99 & -0.006 & 14.5 & 0.0124 \\
\hline \multirow{5}{*}{ Maglie } & Average & 4.18 & -0.035 & 13.4 & 0.0077 \\
\hline & Std. dev. & 4.68 & 0.034 & 14.7 & 0.0091 \\
\hline & Median & 2.49 & -0.023 & 8.8 & 0.0055 \\
\hline & 25th quartile & 0.87 & -0.052 & 5.7 & 0.0024 \\
\hline & 75th quartile & 5.78 & -0.008 & 14.2 & 0.0096 \\
\hline & & $\mathrm{Vd}(\mathrm{mm} / \mathrm{s})$ & Flux $\left(\# / \mathrm{cm}^{2} \mathrm{~s}\right)$ & Conc. $\left(\# / \mathrm{cm}^{3}\right)$ & $\mathrm{Vd} / u^{*}$ \\
\hline \multirow{5}{*}{ Antarctica } & Average & 1.17 & -89.2 & 1233.5 & 0.0095 \\
\hline & Std. dev. & 1.55 & 97.6 & 1029.7 & 0.0107 \\
\hline & Median & 0.62 & -56.7 & 960.7 & 0.0059 \\
\hline & 25th quartile & 0.25 & -119.6 & 423.3 & 0.0028 \\
\hline & 75th quartile & 1.51 & -23.9 & 1762.5 & 0.0121 \\
\hline \multirow{5}{*}{ Bologna } & Average & 1.85 & -2312.3 & 12599.3 & 0.0124 \\
\hline & Std. dev. & 2.43 & 3387.9 & 5798.3 & 0.0208 \\
\hline & Median & 1.03 & -1200.0 & 11813.0 & 0.0063 \\
\hline & 25th quartile & 0.42 & -2872.1 & 8400.4 & 0.0027 \\
\hline & 75th quartile & 2.25 & -459.9 & 15638.0 & 0.0133 \\
\hline \multirow{5}{*}{ Lecce 2010} & Average & 5.77 & -9718.7 & 12203.1 & 0.0122 \\
\hline & Std. dev. & 5.74 & 18611.6 & 10821.5 & 0.0113 \\
\hline & Median & 4.01 & -3352.9 & 7266.9 & 0.0091 \\
\hline & 25th quartile & 1.47 & -7648.1 & 5397.4 & 0.0038 \\
\hline & 75th quartile & 7.87 & -1074.2 & 16887.1 & 0.0174 \\
\hline
\end{tabular}

Victoria Land (Antarctica). The NIS is a permanently frozen branch of the Ross Sea that penetrates into a region of about $35 \times 70 \mathrm{~km}^{2}$, surrounded by complex topography. Because of its remote inland location, the site appears ideal for sampling unperturbed atmospheric aerosol characteristics (Figure 1(d)). The campaign was performed throughout the period from 8 to 31 December 2006; the micrometeorological tower (12 $\mathrm{m}$ height) was located at a distance of about $50 \mathrm{~km}$ from the open sea $\left(74^{\circ} 30^{\prime} 02.0^{\prime \prime} \mathrm{S}, 163^{\circ} 27^{\prime} 30.0^{\prime \prime} \mathrm{E}\right)$. More details on the site can be found in [19].

2.5. Maglie Urban Site (South-Eastern Italy). The measurement site was located in the NE boundary of the town of Maglie in the Apulia regions in the SE of Italy $\left(40^{\circ} 07^{\prime} 38.39^{\prime \prime} \mathrm{N}, 18^{\circ} 17^{\prime} 59.50^{\prime \prime} \mathrm{E}\right)$. The site could be considered an urban background site influenced by an industrial area. The town is extending mainly in the sector of wind direction between SE and SW and the countryside is in the sector between $\mathrm{NNO}$ and $\mathrm{E}$. In the town direction the site is characterized by the presence of small buildings (1-2 storeys) and roads with relatively high traffic volume (Figure 1(f)). Five measurement campaigns have been performed (January 2004, December 2004, December 2006, December 2007, and September 2008) for a total of 101 measurement days. These datasets are analysed together in this work. More information can be found in [34].

\section{Instrument Setup}

In all the experimental sites, micrometeorological flux systems based on the eddy-covariance (EC) technique were used to measure vertical turbulent fluxes of momentum, tracers, and energy. The measuring station was based on a threedimensional ultrasonic anemometer (R3 Gill Instruments 
TABLE 4: Average (with standard deviation) and median (with 25th and 75th quartiles) values are reported for deposition velocities, fluxes, concentrations, and normalized deposition velocities for each site, separating PM2.5 from particle number data. In this table data is selected for unstable atmospheric stability cases $L<0$ (including quasi-neutral cases).

\begin{tabular}{|c|c|c|c|c|c|}
\hline \multicolumn{6}{|c|}{ Unstable and neutral conditions $(L<0)$} \\
\hline \multicolumn{2}{|c|}{ PM2.5 } & $\mathrm{Vd}(\mathrm{mm} / \mathrm{s})$ & Flux $\left(\mu \mathrm{g} / \mathrm{m}^{2} \mathrm{~s}\right)$ & Conc. $\left(\mu \mathrm{g} / \mathrm{m}^{3}\right)$ & $\mathrm{Vd} / u^{*}$ \\
\hline \multirow{5}{*}{ Venice } & Average & 3.15 & -0.050 & 23.6 & 0.0118 \\
\hline & Std. dev. & 4.04 & 0.072 & 23.2 & 0.0152 \\
\hline & Median & 1.60 & -0.023 & 16.9 & 0.0059 \\
\hline & 25th quartile & 0.57 & -0.059 & 8.5 & 0.0023 \\
\hline & 75th quartile & 3.93 & -0.009 & 30.0 & 0.0144 \\
\hline \multirow{5}{*}{ Lecce 2005} & Average & 5.10 & -0.040 & 10.6 & 0.0102 \\
\hline & Std. dev. & 6.61 & 0.054 & 5.8 & 0.0132 \\
\hline & Median & 2.83 & -0.026 & 10.3 & 0.0053 \\
\hline & 25th quartile & 1.31 & -0.048 & 6.2 & 0.0027 \\
\hline & 75th quartile & 6.07 & -0.013 & 14.7 & 0.0123 \\
\hline \multirow{5}{*}{ Maglie } & Average & 3.77 & -0.039 & 14.3 & 0.0075 \\
\hline & Std. dev. & 3.45 & 0.035 & 12.1 & 0.0075 \\
\hline & Median & 2.32 & -0.025 & 12.5 & 0.0054 \\
\hline & 25th quartile & 1.22 & -0.061 & 7.4 & 0.0019 \\
\hline & 75th quartile & 5.67 & -0.011 & 15.8 & 0.0098 \\
\hline & & $\mathrm{Vd}(\mathrm{mm} / \mathrm{s})$ & Flux $\left(\# / \mathrm{cm}^{2} \mathrm{~s}\right)$ & Conc. $\left(\# / \mathrm{cm}^{3}\right)$ & $\mathrm{Vd} / u^{*}$ \\
\hline \multirow{5}{*}{ Antarctica } & Average & 0.73 & -97.4 & 1762.7 & 0.0108 \\
\hline & Std. dev. & 0.83 & 118.4 & 1182.5 & 0.0122 \\
\hline & Median & 0.41 & -57.3 & 1593 & 0.0078 \\
\hline & 25th quartile & 0.20 & -111.1 & 815.7 & 0.0031 \\
\hline & 75th quartile & 0.83 & -27.3 & 1958.6 & 0.0128 \\
\hline \multirow{5}{*}{ Bologna } & Average & 2.41 & -2883.7 & 11992.1 & 0.0111 \\
\hline & Std. dev. & 2.86 & 3842.4 & 5889.4 & 0.0130 \\
\hline & Median & 1.57 & -1690 & 11059.2 & 0.0070 \\
\hline & 25th quartile & 0.61 & -3787.0 & 7501.3 & 0.0028 \\
\hline & 75th quartile & 3.15 & -530 & 14783.4 & 0.0143 \\
\hline \multirow{5}{*}{ Lecce 2010} & Average & 6.17 & -10502.5 & 12672.3 & 0.0127 \\
\hline & Std. dev. & 5.81 & 19241.5 & 11169.5 & 0.0114 \\
\hline & Median & 4.60 & -3886.2 & 7382.4 & 0.0095 \\
\hline & 25th quartile & 1.88 & -9008.2 & 5385.1 & 0.0043 \\
\hline & 75th quartile & 8.27 & -1420.3 & 17209.7 & 0.0178 \\
\hline
\end{tabular}

Ltd., Lymington, UK), operating at $100 \mathrm{~Hz}$ in calibrated mode. A slow-response thermohygrometer (Rotronic MP100A) was installed in order to measure temperature and relative humidity during the campaigns.

An infrared optical sensor pDR-1200 (Personal Data logging Real Time Aerosol Monitor by Thermo Electron, Mie Corp.) was used to measure PM2.5 concentrations and fluxes during the field campaign in Lecce (2005), Venice lagoon, and Maglie, as reported in Table 1 . The pDR-1200 was operating at $1 \mathrm{~Hz}$ in active sampling $(4 \mathrm{~L} / \mathrm{min})$ and it was equipped with a cyclone $(2.5 \mu \mathrm{m}$ cut-off at the $4 \mathrm{~L} / \mathrm{min}$ flow rate used, model GK2.05) for PM2.5 selection [35]. It was verified that exists a delay $t_{0}$, about $2 \mathrm{~s}$, between change in mass concentration and the effective measure of pDR-1200. This delay has been also verified by searching the maximum of the absolute value of the covariance between the vertical wind velocity and the concentration time-series and it has been taken into account in the evaluation of the turbulent fluxes. Atmospheric aerosol can be highly hygroscopic and it can absorb water vapour at high relative humidity changing dimension, density, and optical properties; this process modifies the scattering and absorption coefficients of particles and then it modifies the response of the optical detector used [36]. Therefore, measured concentrations were corrected, using the procedure described in [33], to take into account the role of relative humidity.

In Antarctica, Bologna, and Lecce (2010) sites (Table 1), instrumental setup included a Condensation Particle Counter (CPC-Grimm Aerosol, model 5.403) that measured the total particle number concentration (PNC) with a sampling frequency of $1 \mathrm{~Hz}$. The performances of this $\mathrm{CPC}$ are analyzed by [37]. The CPC output was connected to the analog inputs of the anemometer by means of a digital-toanalog conversion with a simple two-channel interface. More 
TABLE 5: Average (with standard deviation) and median (with 25th and 75th quartiles) values are reported for deposition velocities, fluxes, concentrations, and normalized deposition velocities for each site, separating PM2.5 from particle number data. In this table data is selected for stable atmospheric stability cases $L>0$ (including quasi-neutral cases).

\begin{tabular}{|c|c|c|c|c|c|}
\hline \multicolumn{6}{|c|}{ Stable and neutral conditions $(L>0)$} \\
\hline \multicolumn{2}{|c|}{ PM2.5 } & $\mathrm{Vd}(\mathrm{mm} / \mathrm{s})$ & Flux $\left(\mu \mathrm{g} / \mathrm{m}^{2} \mathrm{~s}\right)$ & Conc. $\left(\mu \mathrm{g} / \mathrm{m}^{3}\right)$ & $\mathrm{Vd} / u^{*}$ \\
\hline \multirow{5}{*}{ Venice } & Average & 2.42 & -0.028 & 29.9 & 0.0096 \\
\hline & Std. dev. & 5.43 & 0.048 & 27.8 & 0.0157 \\
\hline & Median & 0.64 & -0.012 & 22.0 & 0.0037 \\
\hline & 25th quartile & 0.26 & -0.027 & 8.7 & 0.0015 \\
\hline & 75th quartile & 1.99 & -0.004 & 41.6 & 0.0102 \\
\hline \multirow{5}{*}{ Lecce 2005} & Average & 2.79 & -0.015 & 9.4 & 0.0105 \\
\hline & Std. dev. & 4.83 & 0.024 & 6.2 & 0.0121 \\
\hline & Median & 1.04 & -0.008 & 8.5 & 0.0056 \\
\hline & 25th quartile & 0.34 & -0.019 & 4.3 & 0.0022 \\
\hline & 75th quartile & 2.90 & -0.003 & 13.8 & 0.0122 \\
\hline \multirow{5}{*}{ Maglie } & Average & 4.15 & -0.034 & 13.3 & 0.0075 \\
\hline & Std. dev. & 4.55 & 0.034 & 15.3 & 0.0095 \\
\hline & Median & 2.55 & -0.023 & 7.9 & 0.0055 \\
\hline & 25th quartile & 0.83 & -0.051 & 5.5 & 0.0025 \\
\hline & 75th quartile & 5.72 & -0.007 & 13.5 & 0.0094 \\
\hline & & $\mathrm{Vd}(\mathrm{mm} / \mathrm{s})$ & Flux $\left(\# / \mathrm{cm}^{2} \mathrm{~s}\right)$ & Conc. $\left(\# / \mathrm{cm}^{3}\right)$ & $\mathrm{Vd} / u^{*}$ \\
\hline \multirow{5}{*}{ Antarctica } & Average & 1.32 & -86.5 & 1062.4 & 0.0091 \\
\hline & Std. dev. & 1.70 & 90.2 & 916.6 & 0.0102 \\
\hline & Median & 0.75 & -56.5 & 753.8 & 0.0059 \\
\hline & 25th quartile & 0.33 & -119.1 & 398.5 & 0.0028 \\
\hline & 75th quartile & 1.63 & -22.7 & 1538.9 & 0.0116 \\
\hline \multirow{5}{*}{ Bologna } & Average & 1.43 & -1872.9 & 13067.3 & 0.0134 \\
\hline & Std. dev. & 1.95 & 2920.5 & 5688.3 & 0.0251 \\
\hline & Median & 0.79 & -951.2 & 12365.6 & 0.0059 \\
\hline & 25th quartile & 0.32 & -2090.0 & 9051.0 & 0.0027 \\
\hline & 75th quartile & 1.72 & -388.7 & 16199.3 & 0.0125 \\
\hline \multirow{5}{*}{ Lecce 2010} & Average & 1.27 & -1030.9 & 7002.6 & 0.0073 \\
\hline & Std. dev. & 1.28 & 1420.4 & 1935.5 & 0.0084 \\
\hline & Median & 0.89 & -594.8 & 6877.1 & 0.0038 \\
\hline & 25th quartile & 0.54 & -923.9 & 5912.9 & 0.0020 \\
\hline & 75th quartile & 1.56 & -278.3 & 7469.7 & 0.0086 \\
\hline
\end{tabular}

information about the used instruments configuration is reported in $[19,25]$. The particle losses for the inlet system were calculated according to the formulation of [38] for the laminar flow inside the last part of the inlet and according to [39] for turbulent flow in the large section tube. The results show that the cut-off diameter (at 50\% efficiency), D50, is about $9 \mathrm{~nm}$. Therefore, the system used was able to detect particles of between 9 and $1000 \mathrm{~nm}$ (i.e., the upper limit of the CPC). Like for the pDR-1200, the delay in the inlet tube between concentration and velocity fluctuations was taken into account in the evaluation of the eddy-covariance.

\section{Method and Data Processing}

All datasets have been reduced in the streamlines reference system [40] with three rotations using linear detrending of time-histories in order to remove variations related to synoptic time scales [41] and an averaging time of $30 \mathrm{~min}$. Before the computation of turbulent fluxes, the basic instrumental and physical corrections have been applied to the measured time series. Spikes as well as runs with wind directions contaminated by tower/obstacles distortions were discarded. A stationary test has been performed for data series, after the process of detrending [42], in order to individuate nonstationary cases. The nonstationary cases have been eliminated from successive data analysis and the percentages of occurrence of these cases are reported in Table 2.

Fast measurements allowed us to use eddy-covariance technique separating the aerosol concentration and the vertical wind component into mean values and turbulent 
TABLE 6: Average (with standard deviation) and median (with 25th and 75th quartiles) values are reported for deposition velocities, fluxes, concentrations, and normalized deposition velocities for each site, separating PM2.5 from particle number data. In this table data is selected for strictly stable atmospheric stability cases $z / L>0.1$.

\begin{tabular}{|c|c|c|c|c|c|}
\hline \multicolumn{6}{|c|}{ Strictly stable condition $(z / L>0.1)$} \\
\hline \multicolumn{2}{|c|}{ PM2.5 } & $\mathrm{Vd}(\mathrm{mm} / \mathrm{s})$ & Flux $\left(\mu \mathrm{g} / \mathrm{m}^{2} \mathrm{~s}\right)$ & Conc. $\left(\mu \mathrm{g} / \mathrm{m}^{3}\right)$ & $\mathrm{Vd} / u^{*}$ \\
\hline \multirow{5}{*}{ Venice } & Average & 1.16 & -0.023 & 36.9 & 0.0105 \\
\hline & Std. dev. & 2.28 & 0.033 & 28.9 & 0.0176 \\
\hline & Median & 0.47 & -0.011 & 32.9 & 0.0041 \\
\hline & 25th quartile & 0.19 & -0.021 & 13.3 & 0.0018 \\
\hline & 75th quartile & 1.21 & -0.004 & 53.3 & 0.0108 \\
\hline \multirow{5}{*}{ Lecce 2005} & Average & 1.22 & -0.012 & 11.5 & 0.0102 \\
\hline & Std. dev. & 1.88 & 0.028 & 6.4 & 0.0111 \\
\hline & Median & 0.52 & -0.006 & 11.3 & 0.0056 \\
\hline & 25th quartile & 0.24 & -0.011 & 5.6 & 0.0020 \\
\hline & 75th quartile & 1.36 & -0.002 & 15.8 & 0.0128 \\
\hline \multirow{5}{*}{ Maglie } & Average & 1.08 & -0.030 & 34.6 & 0.0104 \\
\hline & Std. dev. & 1.52 & 0.043 & 24.7 & 0.0182 \\
\hline & Median & 0.69 & -0.011 & 30.7 & 0.0046 \\
\hline & 25th quartile & 0.18 & -0.037 & 15.6 & 0.0016 \\
\hline & 75th quartile & 1.09 & -0.005 & 53.7 & 0.00944 \\
\hline \multicolumn{2}{|c|}{ PNC } & $\mathrm{Vd}(\mathrm{mm} / \mathrm{s})$ & Flux $\left(\# / \mathrm{cm}^{2} \mathrm{~s}\right)$ & Conc. $\left(\# / \mathrm{cm}^{3}\right)$ & $\mathrm{Vd} / u^{*}$ \\
\hline \multirow{5}{*}{ Antarctica } & Average & 1.15 & -81.2 & 1101.0 & 0.0091 \\
\hline & Std. dev. & 1.56 & 93.3 & 861.8 & 0.0109 \\
\hline & Median & 0.63 & -48.0 & 882.0 & 0.0055 \\
\hline & 25th quartile & 0.25 & -114.1 & 401.0 & 0.0027 \\
\hline & 75th quartile & 1.34 & -19.8 & 1633.9 & 0.0104 \\
\hline \multirow{5}{*}{ Bologna } & Average & 1.24 & -1802.3 & 13989.4 & 0.0160 \\
\hline & Std. dev. & 1.69 & 2970.2 & 5685.7 & 0.0288 \\
\hline & Median & 0.71 & -929.3 & 13383.9 & 0.0070 \\
\hline & 25th quartile & 0.31 & -1928.9 & 10140.0 & 0.0030 \\
\hline & 75th quartile & 1.42 & -380.0 & 16541.0 & 0.0147 \\
\hline \multirow{5}{*}{ Lecce 2010} & Average & 1.36 & -1241.9 & 7811.3 & 0.0057 \\
\hline & Std. dev. & 1.56 & 1723.4 & 1861.4 & 0.0087 \\
\hline & Median & 0.86 & -608.8 & 7178.1 & 0.0024 \\
\hline & 25th quartile & 0.08 & -1385.9 & 6878.6 & 0.0001 \\
\hline & 75th quartile & 1.98 & -55.0 & 8149.4 & 0.0069 \\
\hline
\end{tabular}

fluctuations [43]. It is useful to normalize aerosol fluxes using the aerosol concentrations obtaining the deposition velocity:

$$
\mathrm{Vd}=-\frac{\overline{w^{\prime} C^{\prime}}}{\bar{C}}
$$

where $w^{\prime}$ are the fluctuations of the vertical wind velocity, $C^{\prime}$ the fluctuations in aerosol concentrations, and $\bar{C}$ the average aerosol concentration. The averaging period for application of the eddy-covariance was 30 minutes for all the measurement campaigns. In the measurement campaigns analysing PM2.5 fluxes, $C$ was a mass concentration of PM2.5; in cases in which the particle number fluxes were analysed, $C$ was the particle number concentration. EC measurements with wind velocities lower than $0.5 \mathrm{~m} / \mathrm{s}$ (wind calm) were removed as they are considered unreliable for calculation of fluxes due to low turbulent mixing.
In the campaigns in which the measurements of latent heat fluxes were available the aerosol fluxes were corrected for variation in air density due to the water vapour fluxes following [44]. No correction was made for variation in density due to heat flux, because heat fluctuations are assumed to be dissipated in the inlet tube [45]. The amounts of these corrections are reported in Table 2.

Measured aerosol fluxes were also corrected for the high frequency losses due to the limited time response of the instruments used. The first-order time response of the pDR1200 used for measurements of PM2.5 fluxes was $1.1 \mathrm{~s}$ and that of the CPC used for measurements of particle number fluxes was $1.3 \mathrm{~s}$. The correction of high frequency losses was performed following the method proposed in [46]. However, in the Antarctica dataset, this method of correction appears to give an overestimation of the correction likely due to the strongly stable conditions. Thus an alternative 
method was developed that used a low-pass digital filter (firstorder Butterworth) approximating the CPC response to a concentration step measured in laboratory as discussed in [19]. The strengths of the high frequency loss corrections are reported in Table 2.

\section{Results}

Dry deposition velocities have been analysed selecting downward fluxes for the different datasets to separate emission (upward fluxes often associated with local sources) from deposition processes $[47,48]$. In general, under turbulence conditions, especially during daytime, dry deposition is controlled by the settling velocity, aerodynamic resistance, turbulent diffusion of the particles (Brownian motion), and their impaction and interception [26]. In general terms the deposition velocity is often parameterised as function of the friction velocity and of atmospheric stability $[12,13,15]$. Specifically, it parameterised the ratio $\mathrm{Vd} / \mathrm{u}^{*}$ as a function of $L$. In Figure 2, the dependence of Vd on friction velocity $u^{*}$ for each dataset referring to PM2.5 mass fluxes is reported. Results in Figures 2 and 3 are obtained segregating the data in intervals of $u^{*}$. Different intervals of $u^{*}$ were selected to optimize the number of data points within each interval and, in each interval, the average and the standard error of Vd were calculated. In Figures 2 and 3 the horizontal bars represent the intervals in friction velocity and the vertical bars represent the standard error of the average deposition velocity within the specific interval of $u^{*}$. In Figure 2, four cases have been separated: all stabilities, only cases with $L>$ 0 , only cases with $L<0$, and only cases in strictly stable conditions $(z / L>0.1$ with $z$ indicating the measurement height). In Figure 3 the same analysis is reported for particle number fluxes. These figures show that even if there is some scatter in the data, deposition velocity grows with friction velocity both for PM2.5 and for particle number fluxes, even if they are measured with different instruments and over different surfaces. This growth is almost up to a friction velocity of $u^{*}=1 \mathrm{~m} / \mathrm{s}$. Other studies also displayed a linear or close to linear dependence of $\mathrm{Vd}$ on $u^{*}$ for particles in the accumulation mode $[15,22,43]$. Results in Figure 2(b) show that at the urban site the increase of $\mathrm{Vd}$ at low $u^{*}$ (lower than $0.2-0.3 \mathrm{~m} / \mathrm{s}$ ) is quite limited especially in stable cases. This could be due to a larger influence of urban obstacles and differences of roughness with wind direction considering that low $u^{*}$ are generally associated with low wind velocities with larger fluctuations in wind direction. Our datasets cannot characterize definitively the dependence of particle fluxes on stability conditions and eventually this dependence may be indirect and expressed by the dependence of $u^{*}$ on atmospheric stratification, although there are some evidences for an increase in particle $\mathrm{Vd}$ in unstable conditions and a reduction with stable or neutral atmospheric stability. As reported in [13], just few studies have been able to quantify the influence of stability with high degree of statistical certainty.

In Table 3, the average (with standard deviation) and median (with 25th and 75th quartiles) values are reported for deposition velocities, fluxes, concentrations, and normalized deposition velocities $\left(\mathrm{Vd} / u^{*}\right)$ considering whole dataset, that is, data in every atmospheric stability conditions. In Table 4 the same variables are reported for a selection of cases in unstable and quasineutral atmospheric conditions $(L<0)$. In Table 5 the same variables are reported for a selection of cases in stable and quasineutral atmospheric conditions $(L>0)$. Finally, in Table 6 all these variables are reported in conditions of strictly stable atmosphere $(z / L>0.1)$. Results show minimal differences in the ratio $\mathrm{Vd} / u^{*}$ measured with different instruments over grass, water, iced land, or built and patched surfaces even if the actual values of $\mathrm{Vd}$ and $u^{*}$ are significantly different. This probably is due to the fact that friction velocity carries most of the information regarding the surface effects. Further, a significant difference between average and median values that is likely associated with the nonsymmetrical distributions of $\mathrm{Vd} / u^{*}$ and with the sensitivity of average values to outliers is observed. The effects of postprocessing and the detailed response of the instruments could be further analysed and results show a certain scatter in $\mathrm{Vd} / \mathrm{u}^{*}$ values, as observed also in [29]. The results seem to indicate that a first parameterisation of $\mathrm{Vd}$, for example, to be used in pollution transport and dispersion modelling, could be based on using the $\mathrm{Vd} / u^{*}$ ratio with a constant value or differentiating two values: one for stable conditions and the other for unstable/neutral conditions. Considering together all the datasets, an average value of $\mathrm{Vd} / u^{*}$ equal to $0.010 \pm 0.0017$ (median value $0.0062 \pm 0.0015$ ) represents the cases for all stabilities. This value is reduced to $0.0097 \pm 0.002$ (median value $0.005 \pm 0.001$ ) considering cases with $L>0$.

\section{Conclusions}

Dry deposition of particles is a key process in atmospheresurface exchange. The analysis and the parameterization of the processes affecting vertical transport and exchange of particles are a relevant research topic for air quality dispersion modelling and for climate modelling. There are several factors influencing dry deposition of aerosol, mainly the friction velocity, the particle size, boundary layer conditions (turbulence intensity), atmospheric stability, and collecting properties of the surface. In this work, an analysis of the correlation between dry deposition velocities, taken over different surfaces, and friction velocities as function of stability is discussed for both PM2.5 mass fluxes and particle number fluxes. Results indicate that deposition velocity increases almost linearly with the increase of $u^{*}$, up to a friction velocity of around $1 \mathrm{~m} / \mathrm{s}$. This happens with similar slopes for PM2.5 fluxes and for particle number fluxes measured with different instruments over the different surfaces. This means that the average ratio $\mathrm{Vd} / u^{*}$ tends to collapse towards a constant value even if the absolute values of fluxes and concentrations are significantly different. This probably is due to the fact that the friction velocity carries most of the information regarding the surface effects. Only limited effect of stability is observed with a slight reduction of the deposition velocities at fixed $u^{*}$ in stable conditions. Considering together all the datasets, an average value of $\mathrm{Vd} / u^{*}$ equal to $0.010 \pm 0.0017$ (median value $0.0062 \pm 0.0015$ ) represents the cases for all stabilities. 


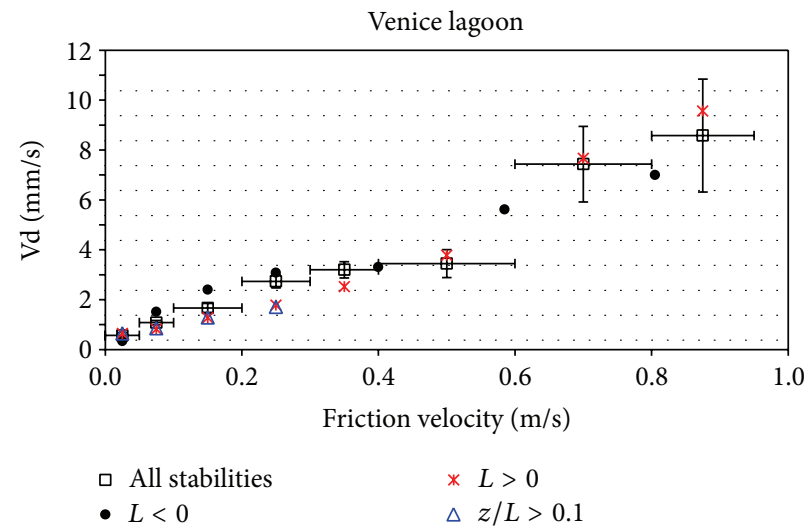

(a)

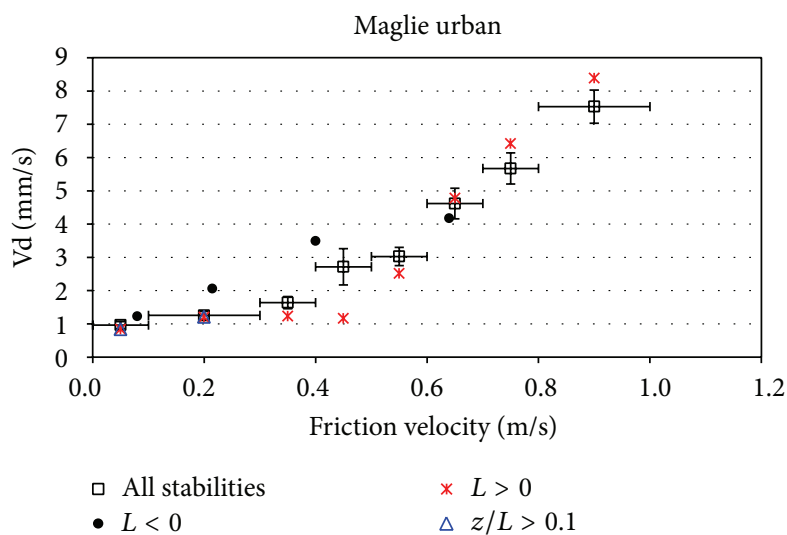

(b)

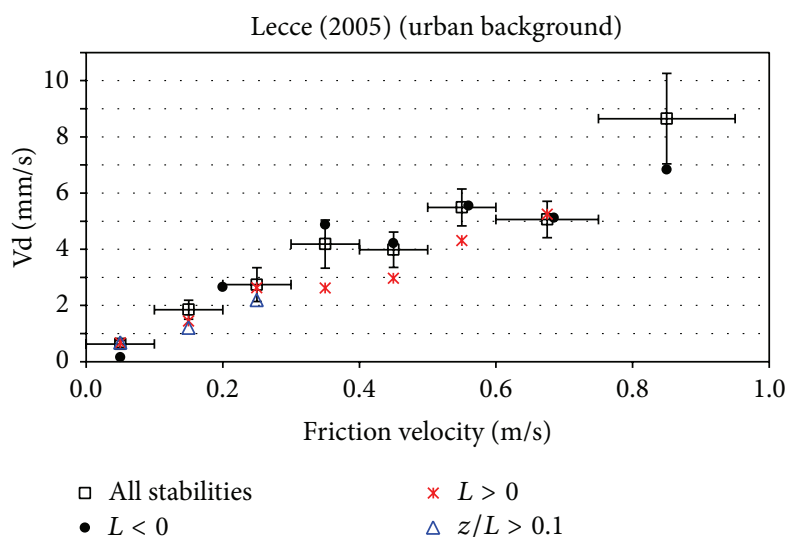

(c)

FIGURE 2: Functional dependence of deposition velocity (Vd) from friction velocity $\left(u^{*}\right)$ for different measurement datasets (as reported in the title of each graph) for PM2.5 mass concentration. Error bars represent standard errors. 


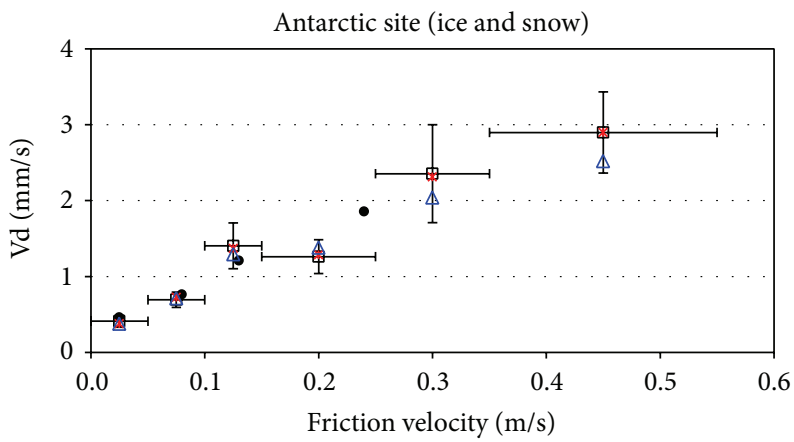

․ All stabilities

* $L>0$

- $L<0$

$\triangle z / L>0.1$

(a)

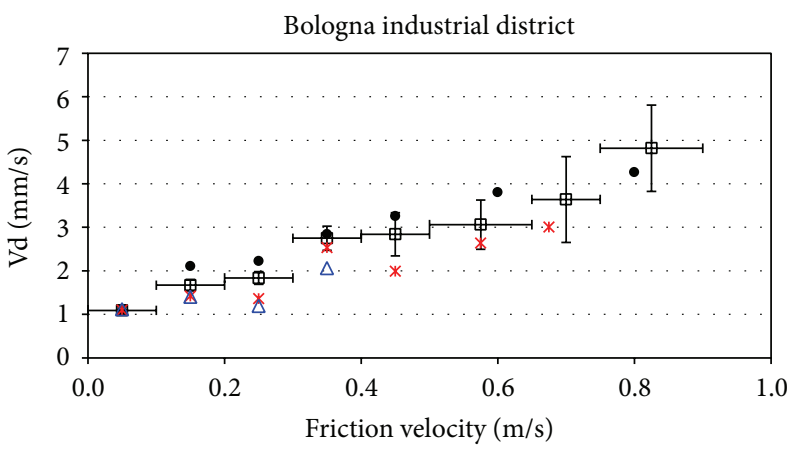

口 All stabilities

- $L<0$

* $L>0$

$\triangle z / L>0.1$

(b)

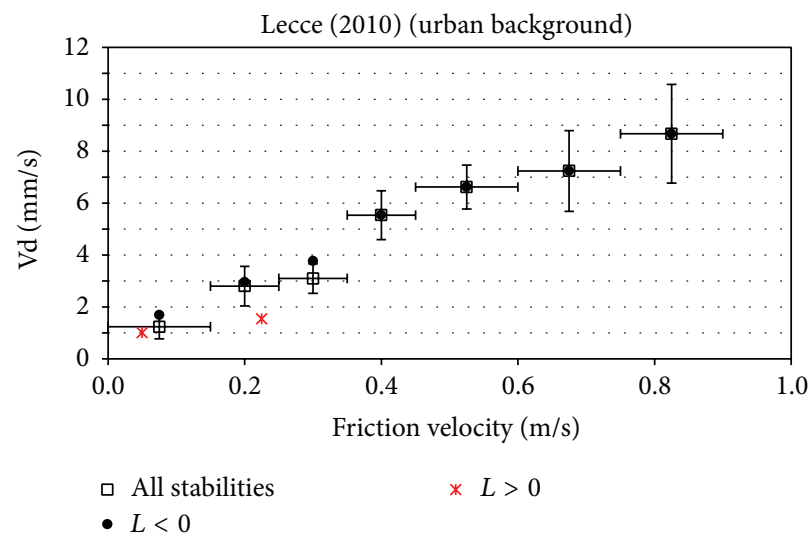

(c)

FIGURE 3: Functional dependence of deposition velocity (Vd) from friction velocity $\left(u^{*}\right)$ for different measurement datasets (as reported in the title of each graph) for particle number concentration (PNC). Error bars represent standard errors. 
This value is reduced to $0.0097 \pm 0.002$ (median value $0.005 \pm 0.001$ ) considering cases with $L>0$. This could be a relatively simple parameterisation to be used in transport and dispersion modelling for simulations over different surfaces.

\section{Conflict of Interests}

The authors declare that there is no conflict of interests regarding the publication of this paper.

\section{Acknowledgments}

The authors wish to thank Ing. F. M. Grasso (ISAC-CNR) and Ing. C. Elefante (University of Salento) for their help in performing the measurements. Further, the authors wish to thank Dr. F. Belosi (ISAC-CNR) for the useful discussion in the interpretation of results.

\section{References}

[1] J. H. Seinfeld and S. N. Pandis, Atmospheric Chemistry and Physics: From Air Pollution To Climate Change, John Wiley \& Sons, New York, NY, USA, 2006.

[2] S. Solomon, D. Qin, M. Manning et al., Climate Change 2007: The Physical Science Basis, Cambridge University Press, Cambridge, UK, 2007.

[3] I. S. A. Isaksen, C. Granier, G. Myhre et al., "Atmospheric composition change: climate-chemistry interactions," Atmospheric Environment, vol. 43, no. 33, pp. 5138-5192, 2009.

[4] W. C. Malm, "Fundamentals of visibility," in Handbook of Weather, Climate and Water: Atmospheric Chemistry, Hydrology, and Societal Impacts, D. T. Potter and B. R. Colman, Eds., pp. 285-329, John Wiley \& Sons, Hoboken, NJ, USA, 2003.

[5] F. Dominici, R. D. Peng, M. L. Bell et al., "Fine particulate air pollution and hospital admission for cardiovascular and respiratory diseases," The Journal of the American Medical Association, vol. 295, no. 10, pp. 1127-1134, 2006.

[6] R. D. Brook, S. Rajagopalan, C. A. Pope et al., "Particulate matter air pollution and cardiovascular disease: an update to the scientific statement from the American Heart Association," Circulation, vol. 121, no. 21, pp. 2331-2378, 2010.

[7] J. J. Corbett, J. J. Winebrake, E. H. Green, P. Kasibhatla, V. Eyring, and A. Lauer, "Mortality from ship emissions: a global assessment," Environmental Science and Technology, vol. 41, no. 24, pp. 8512-8518, 2007.

[8] R. J. Delfino, C. Sioutas, and S. Malik, "Potential role of ultrafine particles in associations between airborne particle mass and cardiovascular health," Environmental Health Perspectives, vol. 113, no. 8, pp. 934-946, 2005.

[9] M. L. Wesely and B. B. Hicks, "A review of the current status of knowledge on dry deposition," Atmospheric Environment, vol. 34, no. 12-14, pp. 2261-2282, 2000.

[10] C. Textor, M. Schulz, S. Guibert et al., "Analysis and quantification of the diversities of aerosol life cycles within AeroCom," Atmospheric Chemistry and Physics, vol. 6, no. 7, pp. 1777-1813, 2006.

[11] M. Kanakidou, J. H. Seinfeld, S. N. Pandis et al., "Organic aerosol and global climate modelling: a review," Atmospheric Chemistry and Physics, vol. 5, no. 4, pp. 1053-1123, 2005.
[12] M. W. Gallagher, E. Nemitz, J. R. Dorsey et al., "Measurements and parameterizations of small aerosol deposition velocities to grassland, arable crops, and forest: influence of surface roughness length on deposition," Journal of Geophysical Research D: Atmospheres, vol. 107, no. 12, pp. 1-10, 2002.

[13] S. C. Pryor, M. Gallagher, H. Sievering et al., "A review of measurement and modelling results of particle atmospheresurface exchange," Tellus B: Chemical and Physical Meteorology, vol. 60, no. 1, pp. 42-75, 2008.

[14] G. Buzorius, Ü. Rannik, J. M. Mäkelä, T. Vesala, and M. Kulmala, "Vertical aerosol particle fluxes measured by eddy covariance technique using condensational particle counter," Journal of Aerosol Science, vol. 29, no. 1-2, pp. 157-171, 1998.

[15] M. W. Gallagher, K. M. Beswick, J. Duyzer, H. Westrate, T. W. Choularton, and P. Hummelshøj, "Measurements of aerosol fluxes to speulderforest using a micrometeorological technique," Atmospheric Environment, vol. 31, no. 3, pp. 359-373, 1997.

[16] B. Duan, W. Fairall, and D. W. Thomson, "Eddy correlation measurements of the dry deposition of particles in wintertime," Journal of Applied Meteorology, vol. 27, pp. 642-652, 1998.

[17] A. Grönlund, D. Nilsson, I. K. Koponen, A. Virkkula, and M. E. Hansson, "Aerosol dry deposition measured with eddycovariance technique at Wasa and Aboa, Dronning Maud Land, Antarctica," Annals of Glaciology, vol. 35, pp. 355-361, 2002.

[18] E. D. Nilsson and Ü. Rannik, "Turbulent aerosol fluxes over the Arctic Ocean 1. Dry deposition over sea and pack ice," Journal of Geophysical Research D: Atmospheres, vol. 106, no. 23, pp. 3212532137, 2001.

[19] D. Contini, A. Donateo, F. Belosi, F. M. Grasso, G. Santachiara, and F. Prodi, "Deposition velocity of ultrafine particles measured with the Eddy-Correlation method over the Nansen Ice Sheet (Antarctica)," Journal of Geophysical Research D: Atmospheres, vol. 115, no. 16, Article ID D16202, 2010.

[20] J. R. Dorsey, E. Nemitz, M. W. Gallagher et al., "Direct measurements and parameterisation of aerosol flux, concentration and emission velocity above a city," Atmospheric Environment, vol. 36, no. 5, pp. 791-800, 2002.

[21] E. M. Mårtensson, E. D. Nilsson, G. Buzorius, and C. Johansson, "Eddy covariance measurements and parameterisation of traffic related particle emissions in an urban environment," Atmospheric Chemistry and Physics, vol. 6, no. 3, pp. 769-785, 2006.

[22] E. Nemitz, J. L. Jimenez, J. A. Huffman et al., "An eddycovariance system for the measurement of surface/atmosphere exchange fluxes of submicron aerosol chemical species-first application above an urban area," Aerosol Science and Technology, vol. 42, no. 8, pp. 636-657, 2008.

[23] A. Schmidt and O. Klemm, "Direct determination of highly size-resolved turbulent particle fluxes with the disjunct eddy covariance method and a 12 stage electrical low pressure impactor," Atmospheric Chemistry and Physics, vol. 8, no. 24, pp. 7405-7417, 2008.

[24] L. Järvi, Ü. Rannik, I. Mammarella et al., "Annual particle flux observations over a heterogeneous urban area," Atmospheric Chemistry and Physics, vol. 9, no. 20, pp. 7847-7856, 2009.

[25] D. Contini, A. Donateo, C. Elefante, and F. M. Grasso, "Analysis of particles and carbon dioxide concentrations and fluxes in an urban area: correlation with traffic rate and local micrometeorology," Atmospheric Environment, vol. 46, pp. 25-35, 2012.

[26] W. G. N. Slinn, "Predictions for particle deposition to vegetative canopies," Atmospheric Environment, vol. 16, no. 7, pp. 17851794, 1982. 
[27] A. Petroff, A. Mailliat, M. Amielh, and F. Anselmet, "Aerosol dry deposition on vegetative canopies. Part I: review of present knowledge," Atmospheric Environment, vol. 42, no. 16, pp. 36253653, 2008.

[28] A. Petroff and L. Zhang, "Development and validation of a size-resolved particle dry deposition scheme for application in aerosol transport models," Geoscientific Model Development, vol. 3, pp. 753-769, 2010.

[29] A. Lavi, D. K. Farmer, E. Segre et al., "Fluxes of fine particles over a semi-arid pine forest: possible effects of a complex terrain," Aerosol Science and Technology, vol. 47, no. 8, pp. 906-915, 2013.

[30] M. Toda and M. Sugita, "Single level turbulence measurements to determine roughness parameters of complex terrain," Journal of Geophysical Research D: Atmospheres, vol. 108, no. 12, 2003.

[31] A. Donateo, D. Contini, F. Belosi et al., "Characterisation of PM2.5 concentrations and turbulent fluxes on a island of the Venice lagoon using high temporal resolution measurements," Meteorologische Zeitschrift, vol. 21, no. 4, pp. 385-398, 2012.

[32] D. Cava, D. Contini, A. Donateo, and P. Martano, "Analysis of short-term closure of the surface energy balance above short vegetation," Agricultural and Forest Meteorology, vol. 148, no. 1, pp. 82-93, 2008.

[33] A. Donateo, D. Contini, and F. Belosi, "Real time measurements of PM2.5 concentrations and vertical turbulent fluxes using an optical detector," Atmospheric Environment, vol. 40, no. 7, pp. 1346-1360, 2006.

[34] D. Contini, A. Donateo, D. Cesari, F. Belosi, and S. Francioso, "Identification and characterisation of local aerosol sources using high temporal resolution measurements," Journal of Environmental Monitoring, vol. 12, no. 9, pp. 1709-1721, 2010.

[35] L. C. Kenny and R. A. Gussman, "Characterization and modelling of a family of cyclone aerosol preseparators," Journal of Aerosol Science, vol. 28, no. 4, pp. 677-688, 1997.

[36] B. Chakrabarti, P. M. Fine, R. Delfino, and C. Sioutas, "Performance evaluation of the active-flow personal DataRAM PM2.5 mass monitor (Thermo Anderson pDR-1200) designed for continuous personal exposure measurements," Atmospheric Environment, vol. 38, no. 20, pp. 3329-3340, 2004.

[37] M. Heim, G. Kasper, G. P. Reischl, and C. Gerhart, "Performance of a new commercial electrical mobility spectrometer," Aerosol Science and Technology, vol. 38, supplement 2, pp. 3-14, 2004.

[38] P. A. Baron and K. Willeke, Aerosol Measurement: Principles, Techniques, and Applications, John Wiley \& Sons, 2nd edition, 2001.

[39] W. C. Hinds, Aerosol Technology: Properties, Behavior, and Measurement of Airborne Particles, John Wiley \& Sons, 2nd edition, 1999.

[40] R. T. McMillen, "An eddy correlation technique with extended applicability to non-simple terrain," Boundary-Layer Meteorology, vol. 43, no. 3, pp. 231-245, 1988.

[41] Ü. Rannik and T. Vesala, "Autoregressive filtering versus linear detrending in estimation of fluxes by the eddy covariance method," Boundary-Layer Meteorology, vol. 91, no. 2, pp. 259280, 1999.

[42] L. Mahrt, "Flux sampling errors for aircraft and towers," Journal of Atmospheric and Oceanic Technology, vol. 15, no. 2, pp. 416429, 1998.

[43] E. Lamaud, A. Chapuis, J. Fontan, and E. Serie, "Measurements and parameterization of aerosol dry deposition in a semi-arid area," Atmospheric Environment, vol. 28, no. 15, pp. 2461-2471, 1994.
[44] E. K. Webb, G. I. Pearman, and R. Leuning, "Correction of flux measurements for density effects due to heat and water vapour transfer," Quarterly Journal Royal Meteorological Society, vol. 106, no. 447, pp. 85-100, 1980.

[45] Ü. Rannik, T. Vesala, and R. Keskinen, "On the damping of temperature fluctuations in a circular tube relevant to the eddy covariance measurement technique," Journal of Geophysical Research D: Atmospheres, vol. 102, no. 11, pp. 12789-12794, 1997.

[46] T. W. Horst, "A simple formula for attenuation of eddy fluxes measured with first-order-response scalar sensors," BoundaryLayer Meteorology, vol. 82, no. 2, pp. 219-233, 1997.

[47] P. E. Damay, D. Maro, A. Coppalle et al., "Size-resolved eddy covariance measurements of fine particle vertical fluxes," Journal of Aerosol Science, vol. 40, no. 12, pp. 1050-1058, 2009.

[48] P. Roupsard, M. Amielh, D. Maro et al., "Measurement in a wind tunnel of dry deposition velocities of submicron aerosol with associated turbulence onto rough and smooth urban surfaces," Journal of Aerosol Science, vol. 55, pp. 12-24, 2013. 

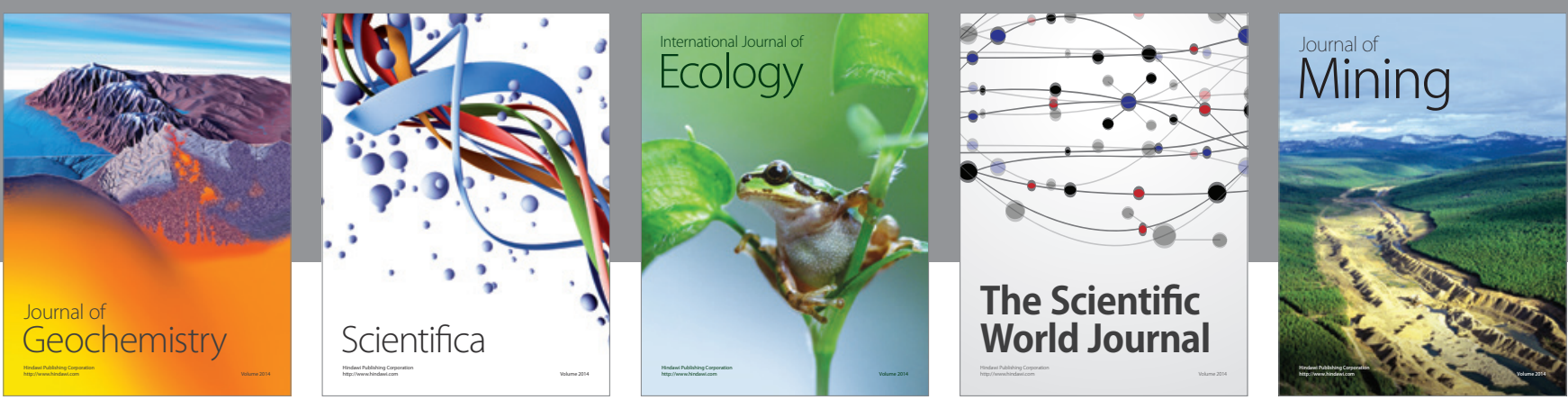

The Scientific World Journal
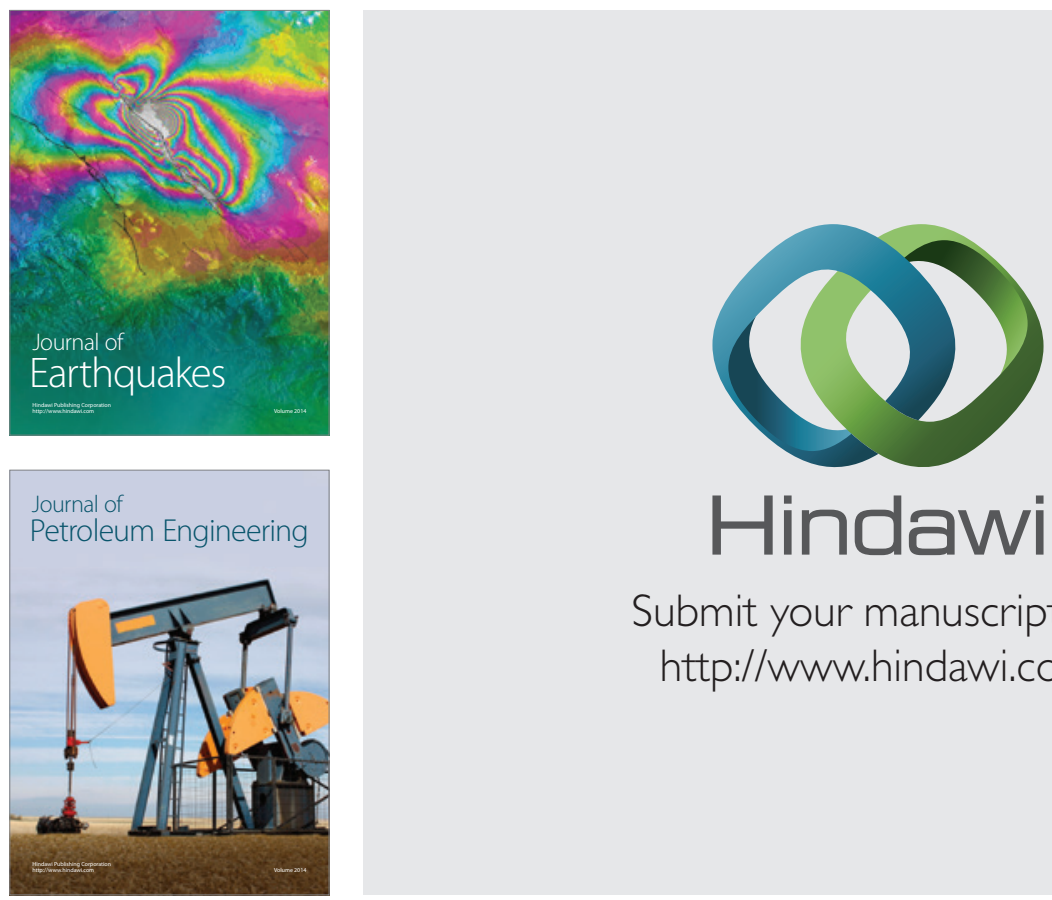

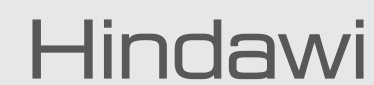

Submit your manuscripts at

http://www.hindawi.com
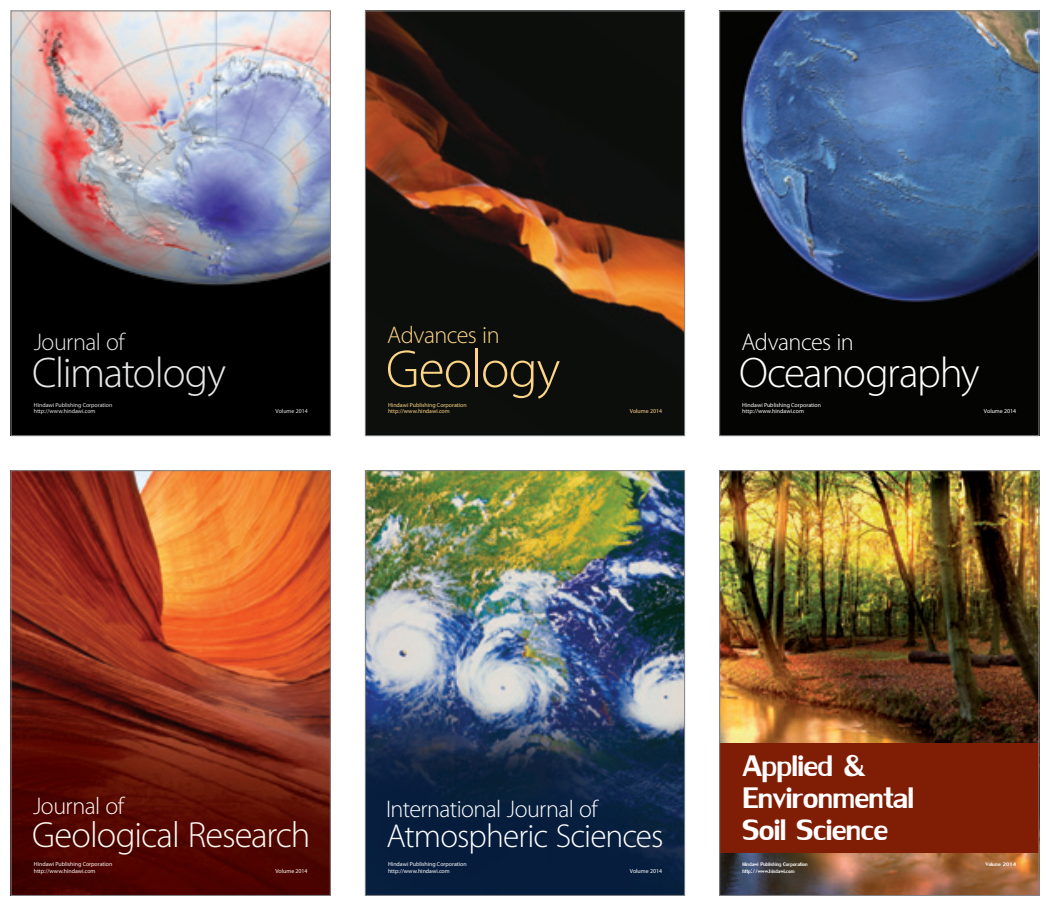
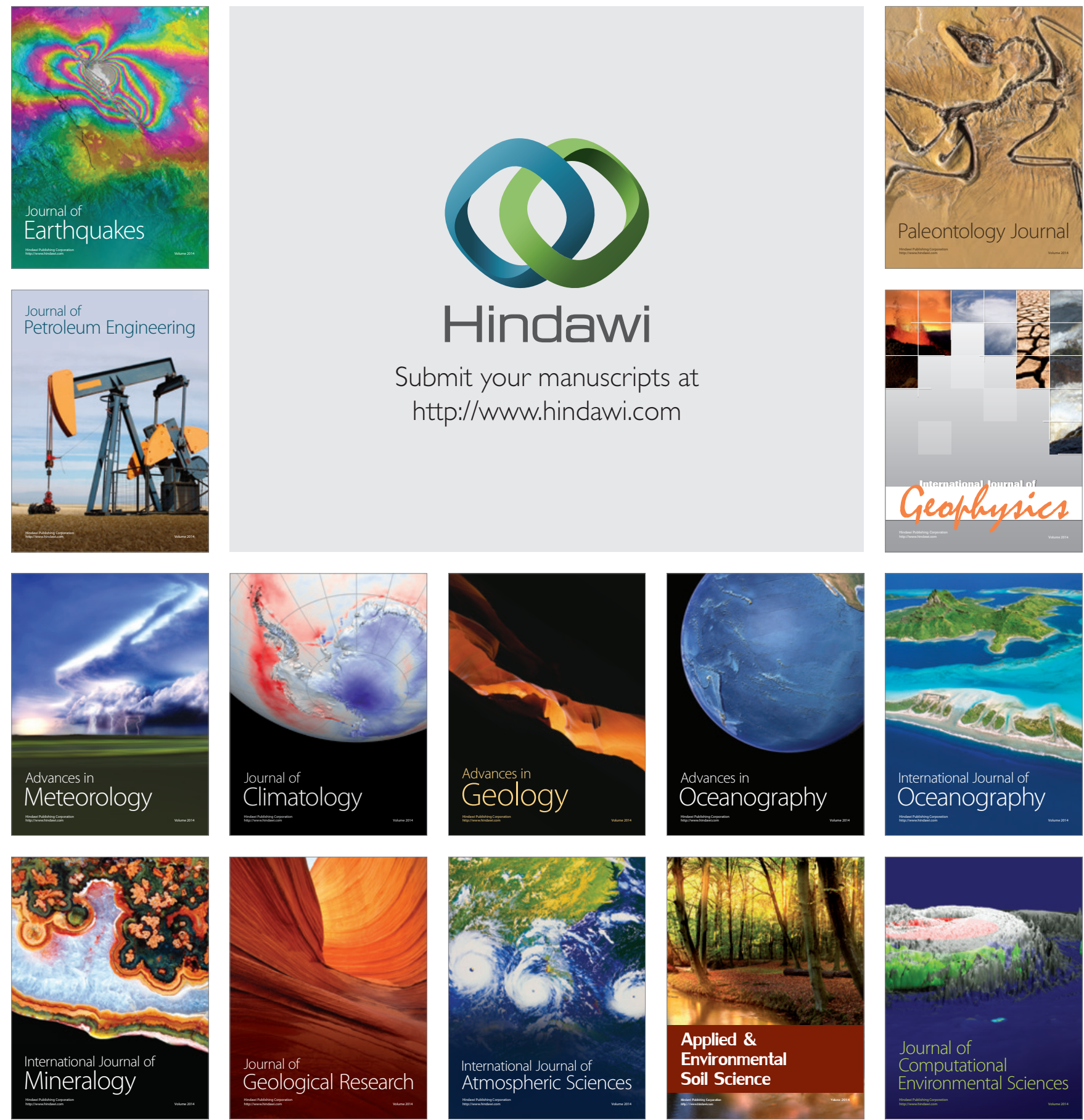